\title{
MIGRANTS’ HEALTH AND ACCESS TO HEALTHCARE IN THE CZECH REPUBLIC
}

\author{
Helena Hnilicová1, Karolina Dobiášová2 \\ ${ }^{1}$ Institute of Public Health and Medical Law, First Faculty of Medicine, Charles University, Prague, Czech Republic \\ ${ }^{2}$ Institute of Sociological Studies, Faculty of Social Sciences, Charles University, Prague, Czech Republic
}

\section{SUMMARY}

The article is dealing with current state of Czech health policy in relation to migration. Overall migration information, available data on migrants' health status as well as accessibility of healthcare are provided. Some health risks connected with migration are mentioned and discussed. Authors concluded that the most urgent problem of Czech health policy in relation to migrants remains the insufficient guarantee of legal entitlement to health care. This concerns a large group of migrants with long-term residence, since the current legal regulation is disadvantageous to migrants coming from countries outside the EU.

Key words: public health, migration, health status, access to healthcare, general health insurance, private health insurance

Address for correspondence: H. Hnilicová, Institute of Public Health and Medical Law, Charles University, Karlovo nám. 40, 12800 Praha 2, Czech Republic. E-mail: hhnil@lf1.cuni.cz

\section{INTRODUCTION}

As a result of discrimination, language and cultural barriers, work in low-grade positions in the risk sectors and due to living conditions on the margin of poverty are migrants considered a vulnerable group with specific medical needs (1). The issue of health and migration is becoming, particularly in developed countries, a recognised issue in developing health policy $(2,3)$ which should assure accessibility and quality of healthcare to migrants and to protect public health of the host country $(3,4)$.

The immigration and the relevant social processes are relatively new, but represent a significant phenomen in a traditionally homogenous Czech environment. Since the 1990s the Czech Republic (CR) is one of the countries with the fastest growing migration. In the period 1990-2006 the number of foreigners in the CR rose almost tenfold (5). Even despite a certain drop in the number of legal and long-term resident foreigners in the $\mathrm{CR}$, which was caused by the economic crisis, there were more than 420,000 foreigners legally in the CR in mid-2010; that is about $4 \%$ of the population (5). It is estimated that a significant number of illegal migrants reside in the country, though their exact number is unknown. Estimates range widely from 15,000-300,000 people (6). Migrants in the CR are predominantly male $-59 \%$. As to the nationality most numerous are Ukrainians $32 \%$, Slovaks $18 \%$, Vietnamese $14 \%$, Russians $7 \%$ and Poles $6 \%$. For a long time the composition of migrants by nationality has remained unchanged. The age structure of migrants reflects the fact that migration for economic reasons prevails and three quarters of migrants (77\%) are therefore in the age category of 20-65 years. Children and young people to 19 years make up $20 \%$, people aged over 65 make up just 3\% (5). Since 1997 the number of children born to foreigners has gradually risen in the $\mathrm{CR}$. All these people are potential beneficiaries of health care, while ensuring its availability is important not only for them, but for protection of public health with respect to general population as well (7).
In terms of health status and accessibility of healthcare it should be considered that migrants do not form a homogenous group. There is a range of subcategories of "migrant" based on the type of migration: students, economic migrants and their families, asylum seekers, refugees, irregular migrants etc. (2, 8). The following article focuses chiefly on economic migrants and their families residing in the Czech Republic long-term and legally.

\section{Health Status of Migrants in the CR}

Information on migrants' health available in the $\mathrm{CR}$ provides only a scanty picture of health and healthcare needs of the growing number of migrants and factors affecting their health. Existing knowledge is not comprehensive enough and does not cover all groups of foreigners equally. In short, there are two basic sources of information in the $\mathrm{CR}$ for a description of the health of migrants. The first are routine statistics and the second are conclusions of a specific research and survey sampling (9-12).

The possibility of using official statistics for describing the health of foreigners as a whole is very limited in the CR, because most routine statistics on mortality and morbidity lack data on ethnic origin. Nevertheless, certain data exist. These mainly concern TBC, sexually transmitted diseases and HIV/AIDS, and institutional psychiatric care. There is also mandatory declaration of work-related injuries which records whether the injured person is a foreigner. Since 2000 the Czech Statistical Office has been monitoring certain data of healthcare utilization by foreigners. However, while interpreting these data a number of limitations needs to be considered. Only the needs for hospital care and only those foreigners who are not insured in the scope of general health insurance are monitored, whereas three quarters of economically active foreigners in the $\mathrm{CR}$ are clients of general health insurance (13). Migrants' consumption of outpatient care is not monitored 
at all. The results of several research projects carried out in the last two decades in the CR can be used to supplement data on the health and healthcare demands of foreigners.

\section{Injuries}

From available statistics and results of migrants' surveyed samples it is clear that one of the most common health risks are injuries which are the most common reasons for their hospitalisation $(5,10,14,15)$. The occurrence of work-related injuries among foreigners is three times higher than in the Czech population according to a comparative survey of subjective evaluation of health and healthcare demands among migrants from the former Soviet Union dating from 2003 (12). In recent years the National Work Inspectorate has recorded an annual growth of work-related injuries among foreigners (16). The higher level of work-related injuries is probably related to the fact that $60 \%$ of migrants are employed in hazardous sectors such as construction and processing industry (5). Among other causes the most important are probably high work load, failure to follow health and safety rules coupled with insufficient language skills.

\section{Infectious Diseases}

The epidemiological situation in terms of most infectious diseases is more or less stabilised and under control. However, despite some positive outcomes, we cannot overlook the fact that some diseases are showing a disquieting growth in recent years.

Statistics show that, despite the growing number of foreigners in the $\mathrm{CR}$, the TBC incidence has been very low and continues to fall (6.8 cases per 100,000 inhabitants in 2009). In recent years proportion of foreigners' share on the total number of TBC infections reported in the Czech Republic has been about 20\% (Table 1). In 2009 most people infected came from the Ukraine and Vietnam. This means that the share of foreigners on the TBC prevalence significantly exceeds their percentage share in Czech population. The epidemiological situation in the CR is thus beginning to resemble the situation in the developed EU countries. Less favourable is the situation in terms of HIV/AIDS. Although the prevalence of this dangerous disease is still relatively low in the CR, a sharp growth in HIV positive individuals has been recorded in recent years. In the last years around quarter of all newly registered patients are foreigners, most frequently from Eastern Europe and Sub-Saharan Africa (18) (Table 2). Sexually transmitted diseases are also significantly more common among foreigners. In the case of syphilis, they represent about a third of all newly diagnosed cases (Table 3 ). In the CR the occurrence of this disease has risen very fast since the beginning of the 1990s and up to 2000 syphilis incidence increased six times (29) and its negative epidemiological impact is also reflected in rise of congenital syphilis among newborns, which used to be very rare in the Czech Republic in 1980s. The risk of the spread of this disease to the Czech population should not be underestimated. For the above reasons, at the initiative of the Ministry of Health and Chief Health Officer, a regulation was adopted in mid-2009 concerning the obligation of selected risk groups of foreigners to present a certification of syphilis and TBC infection absence as part of visa applications.

\section{Migrants' Mental Health in the Czech Republic}

The risk of mental health can be explored through data on treatment of migrants in the Czech psychiatric hospitals. Migrants comprise about $1 \%$ of all patients in Czech psychiatric hospitals. Alcohol, drug abuse and related mental disorders are the most frequent diagnoses, representing more than one third of all hos-

Table 1. Trend of number of notified cases of TB in the Czech Republic - share of foreigners

\begin{tabular}{|l|c|c|c|c|c|c|}
\hline & $\mathbf{2 0 0 1}$ & $\mathbf{2 0 0 5}$ & $\mathbf{2 0 0 6}$ & $\mathbf{2 0 0 7}$ & $\mathbf{2 0 0 8}$ & $\mathbf{2 0 0 9}$ \\
\hline Total & 1349 & 1007 & 973 & 871 & 879 & 710 \\
\hline Number of notified cases of TB in foreigners & 194 & 130 & 130 & 153 & 186 & 136 \\
\hline Share of foreigners of all notified cases & $14 \%$ & $13 \%$ & $13 \%$ & $18 \%$ & $21 \%$ & $19 \%$ \\
\hline
\end{tabular}

Table 2. HIVIAIDS prevalence (cumulative data), 31 January 2011

\begin{tabular}{|l|c|c|c|}
\hline & $\mathbf{2 0 0 8}$ & $\mathbf{2 0 0 9}$ & $\mathbf{2 0 1 0}$ \\
\hline Total & 1856 & 1344 & 1186 \\
\hline Foreigners & 334 & 320 & 304 \\
\hline Share of foreigners in total HIVIAIDS cases & $18 \%$ & $24 \%$ & $26 \%$ \\
\hline
\end{tabular}

Table 3. Trend of notified cases of syphilis - share of foreigners

\begin{tabular}{|l|c|c|c|c|c|c|}
\hline & $\mathbf{2 0 0 1}$ & $\mathbf{2 0 0 5}$ & $\mathbf{2 0 0 6}$ & $\mathbf{2 0 0 7}$ & $\mathbf{2 0 0 8}$ & $\mathbf{2 0 0 9}$ \\
\hline Total & 1396 & 523 & 502 & 822 & 850 & 997 \\
\hline Number of notified cases of syphilis in foreigners & 818 & 210 & 160 & 267 & 240 & 222 \\
\hline Share of foreigners of all notified cases & $59 \%$ & $40 \%$ & $31 \%$ & $32 \%$ & $28 \%$ & $22 \%$ \\
\hline
\end{tabular}


pitalised migrants (20). Alcohol and drug abuse is predominantly a consequence of stress factors connected with migration, e.g. living and working in an unknown and completely new environment (21). As in other destination countries (21) other frequent diagnoses are psychotic disorders representing about quarter of all hospitalised migrants (20).

\section{Migrants' Health, Health Determinants and Health- Care Utilization}

Available routine statistics on healthcare demands of foreigners do not allow a valid comparison of this indicator with the Czech population. Very specific and detailed information on migrants' health in general is available from the surveys investigating migrants' health and healthcare consumption patterns which were performed in recent years. Although these studies were not generalisable, they may provide for some migrants groups relatively complex insights into health and health-related issues. Most of research studies focused on legal migrants from the former USSR, which make up $40 \%$ of all migrants in the CR. Valid and reliable data were provided by a comparative research undertaken in 2003 on subjective perception of health and health determinants, as well as healthcare utilization (12). It was basically a questionnaire sample survey. Data were collected through face-to-face interviews performed by trained inquirers using the native languages of respondents. Equal numbers of migrants and comparable Czechs were balanced according to gender and age ( $\mathrm{N}=1062$, migrants, Czechs). Significant differences were identified between migrants from the former Soviet Union and the comparable sample of Czechs. The results showed a large working load as well as risk working conditions for the workers from the former Soviet Union. As a consequence, the occurrence of work-related injuries was three times as high as compared with the Czechs. Additionally, migrants' lifestyles and health-related behaviour seem to be more risky. There are significantly more smokers among them and also the proportion of heavy smokers is higher. Migrants also indicate a higher consumption of alcohol beverages with preference for spirits. On the other hand, both genders of migrants from the former Soviet Union stated better subjective health, fewer chronic diseases, and fewer health problems and pain suffered. This phenomenon known as "the healthy migrant effect" $(2,22,23)$ was confirmed also for migrants in the Czech Republic. Compared to Czechs they utilize healthcare services substantially less. Among other causes the limited access of migrants to Czech general health insurance has been a significant contributing factor (24). As a consequence, some groups of migrants are at higher risk of not being provided with all health services required and so a negative long-term impact on health is possible.

\section{The Healthcare System and Migrants' Entitlement to Healthcare}

Accessibility of healthcare is a crucial aspect for migrants' integration in the host country (3). For the Czech citizens, healthcare is guaranteed by the Czech Constitution, with the Charter of Fundamental Rights and Basic Freedoms as an integral part of the Constitution. Required healthcare is understood as one of the basic human rights of Czech citizens. The guarantee of this right and availability of healthcare is assured by general health insurance based on solidarity principles. Health insurance contributions have the character of payroll tax divided between employees and employers (1/3-2/3). Children, mothers on maternity leave, pensioners, students (up to 26 years old), the unemployed, poor people living below the poverty line and some other groups of citizens are exempt from paying the contributions; their health insurance is covered by the State. As for migrants, there are some differences in legal entitlement to Czech general health insurance between EU citizens and non-EU citizens. EU citizens residing in the Czech territory have the same access to general health insurance as Czechs do.

By law, all foreigners staying in the Czech Republic on a long-term basis are legally obliged to participate in health insurance throughout their stay. Meeting this condition is required immediately after entering the country. An entry to the country may be refused if a foreigner is unable to prove that he or she has adequate health insurance cover (25). Foreigners may meet this requirement via general or commercial health insurance. General health insurance is available to all persons specified by law (26), for whom it is mandatory. It is available for all legal migrants permanently residing in the $\mathrm{CR}$ and all migrants from the EU staying in the Czech territory more than 90 days (long-term stay). Migrants from non-EU countries (without permanent residence) can participate in general health insurance as long as they work in the CR with the status of employee, i.e. they are employed by any company or any institution registered in the Czech Republic. All other migrants from third countries are obliged to purchase commercial health insurance offered by the several Czech commercial insurance bodies. They are the following migrants' groups: self-employed persons, all children up to 18, parents and partners of non-EU migrants (if they are not EU citizens or they haven't got permanent residence permits), students not covered by international agreements and some others. The total number of all these migrants is estimated at 100,000-120,000 persons, which represents about one quarter of the overall number of migrants in the Czech Republic $(5,27)$.

\section{Migrants' Commercial Health Insurance}

In comparison to general health insurance, conditions of commercial health insurance are significantly worse for migrants; this insurance is not generally of interest to them. It works according to market principles. The scope of care covered is not practically regulated by law. It is only required to cover medical expenses amounting to $€ 60,000$ at minimum; up to this amount co-payment is not possible for healthcare covered by the insurance contract (25). According to market principles, the insurance contract takes into account the risks of the insured individual, namely in a form of the insurance premium's scope. It is possible that some risky applicants will be refused and will remain uninsured, including people with higher health risks or children with congenital defects and/or chronic diseases $(11,24,28)$. Commercial health insurance does not cover a sufficient scope of care; it is particularly insufficient in cases of serious illness. With commercial insurance there are frequent exclusions and limits of cover which are very complicated and difficult to understand for people without legal education, as well as perfect language knowledge or orientation in the Czech healthcare system. For example, it does not include 
insulin-dependent diabetes, chronic renal insufficiency and haemodialysis and some other diseases (see below). It basically covers mainly emergency care in the case of acute illness and injury. There is a maximum limit of payout, the premium increases as the insured person gets older, and people over 70 are not ussually insurable for a reasonable price. Insurance premiums are paid by lump sum for the whole insured period in advance (up to two years), which is a great financial burden particularly for migrant families with children. It is paradoxical that some serious diseases for which there is mandatory treatment in the CR are explicitly excluded from all available kinds of commercial insurance. This concerns illnesses when the sick patient may be dangerous to himself or his surroundings and therefore his/her hospitalisation and treatment is necessary. These are primarily psychiatric illnesses but also drug addiction and illnesses connected with alcohol abuse. Fortunately due to ammendment of the Immigration Act in December 2010 psychiatric care has already been covered. Also excluded are sexual and sexually transmitted diseases including HIV/AIDS, which treatment for obvious reasons is mandatory in accordance with the Act No. 258/2000 on the protection of public health. Routine dental care is not included in standard insurance, but supplementary insurance is possible. Generally, prematurely born children or children born disabled or with congenital defects are considered as the most vulnerable groups, since they may remain uninsured in a situation of urgent need for intensive neonatal care. Despite of this fact, imperative intensive care is fully provided for such children in practice. By the law as well as in accordance with medical ethics, Czech physicians are obliged to provide all care required to such children under the same conditions as for any other children. The problem is that in some cases nobody pays for it. It is a reality that a part of necessary care provided to migrants remains financially unsettled $(5,14,15,28)$. Elimination of these existing inequalities in access to general health insurance is targeted in the Czech government migration policy agenda as one of the priorities. Currently (December 2010) the Czech Parliament adopted an amendment to the Immigration Act which reacts to some existing problems. For example, commercial insurance companies will no longer be able to apply some exclusions from insurance coverage and health insurance for long-term residence has to guarantee health care up to the level of $€ 60,000$. For many years before it was only half of this amount $€ 30,000$.

\section{CONCLUSIONS}

The most urgent problem of Czech health policy in relation to migrants remains the insufficient guarantee of legal entitlement to health care. This concerns the large group of migrants with long-term residence, since the current legal regulation is disadvantageous to migrants coming from countries outside the EU. One of the most important barriers to implementation of effective and evidence-based health policy leading to migrant-sensitive health system has been the lack of objective data and insufficient information on migrants' health and healthcare needs.

\section{Acknowledgement}

This article was written with the financial support of the Charles University Grant Agency as part of project no. 112410 "Health policy in relation to migrants in the CR and in the international context" and specific university research project no. $261511 / 2010$ "Analysis and conception of public and social policy in the Czech Republic in the European Union context".

\section{REFERENCES}

1. Tulchinsky TH, Varavikova EA. The new public health: an introduction for the 21st century. San Diego: Academic Press; 2009.

2. Mladovsky P. A framework for analysing migrant health policies in Europe. Health Policy. 2009 Nov; 93(1):55-63.

3. Ingleby $\mathrm{D}$, et al. Social integration and mobility: education, housing and health. IMISCOE Cluster B5 State of the art report. In: Fonseca L, Malheiros J, editors. Study on Regional and Urban Planning No. 67. Lisbon: Centre of Geographical Studies; 2005. p. 89-119. (In Portuguese.)

4. Mladovsky P. Migrant health in EU. Eurohealth. 2007;13(1):9-11.

5. Czech Statistical Office. Foreigners in the Czech Republic 2009. Prague: Czech Statistical Office; 2010. (In Czech.)

6. Drbohlav D. Illegal economic activities of migrants. Czechia in European Context. Prague: Karolinum; 2009. (In Czech.)

7. Hnilicová H, Dobiášová K. Migrants and public health in the light of the research. In: Ministry of the Interior of the Czech Republic. Contribution and potential of research in the field of migration. Prague: Ministry of the Interior of the Czech Republic; 2010. p. 75-84. (In Czech.)

8. Spallek J, Zeeb H, Razum O. Prevention among immigrants: the example of Germany. BMC Public Health. 2010 Feb 24;10:92.

9. Nesvadbová L, et al. Health, psychological and social aspects of migration. Prague: Ministry of Health of the Czech Republic; 1998. (In Czech.)

10. Nesvadbová L. Study of economic migrants' health status and social problems in 1996-1999. The final research report. Prague: Ministry of Health of the Czech Republic; 2000. (In Czech.)

11. Dobiášová K, Křečková N, Angelovská O. Healthcare of migrants’ children. Reality and practice. Kostelec nad Černými lesy: IZPE; 2006. (In Czech.)

12. Dobiášová $\mathrm{K}$, Vyskočilová O. Migrants' health status and health care utilization in comparison with Czech population. Zdravotnictví v C̆R. 2004 Nov;7(1): 32-9. (In Czech.)

13. Czech Statistical Office. Conception of sampling and data processing related to migration and integration in Czech Republic. Prague: Czech Statistical Office; 2010. (In Czech.)

14. Czech Statistical Office. Foreigners in the Czech Republic 2007. Prague: Czech Statistical Office; 2008. (In Czech.)

15. Czech Statistical Office. Foreigners in the Czech Republic 2008. Prague: Czech Statistical Office; 2009. (In Czech.)

16. Work injuries. MIGHEALTHNET in the CR [Internet]. Prague: Charles University, First Faculty of Medicine - Institute of Public Health and Medical Law [cited 2010 Oct 10 ]. Available from: http://mighealth.net/cz/index.php/Zdravotn\%C3\%AD_stav_podle_ofici $\% \mathrm{C} 3 \% \mathrm{~A} 1 \mathrm{ln} \% \mathrm{C} 3 \% \mathrm{ADch}$ statistik. (In Czech.)

17. Incidence of tuberculosis in the Czech Republic in 2007, 2008, 2009 [Internet]. Prague: Institute of Health Information and Statistics of the Czech Republic; 2010 [cited 2010 Oct 10]. Available from: http://www. uzis.cz. (In Czech.)

18. Report on distribution and spread HIV/AIDS in 2008, 2009, 2010 [Internet]. Prague: National Institute of Public Health; 2010 [cited 2010 Nov 30]. Available from: http://www.szu.cz/tema/prevence/zprava-o-vyskytua-sireni-hiv-aids-za-rok-2010. (In Czech).

19. Venereal diseases in the Czech Republic in 2006, 2008 [Internet]. Prague: Institute of Health Information and Statistics of the Czech Republic; 2010 [cited 2010 Oct 10]. Available from: http://www.uzis.cz.

20. Psychiatric care in the Czech Republic in 2008 [Internet]. Prague: Institute of Health Information and Statistics of the Czech Republic; 2010 [cited 2010 Oct 10]. Available from: http://www.uzis.cz.

21. Carta MG, Bernal M, Hardoy MC, Haro-Abad JM; Report on the Mental Health in Europe Working Group. Migration and mental health in Europe (the state of the mental health in Europe working group: appendix 1). Clin Pract Epidemiol Ment Health. 2005 Aug 31;1:13.

22. Kristiansen M, Mygind A, Krasnik A. Health effects of migration. Dan Med Bull. 2007 Feb;54(1):46-7.

23. McDonald JT, Kennedy S. Insights into the 'healthy immigrant effect' health status and health service use of immigrants to Canada. Soc Sci Med. 2004 Oct;59(8):1613-27. 
24. Hnilicová H, Dobiášová K, Čižinský P. Private health insurance for foreigners [Internet]. Prague: Multicultural Centre Prague; 2010 [cited 2010 Oct 10]. Available from: http://www.migraceonline.cz/eknihovna/?x=2219641. (In Czech.)

25. Act No. 326/1999 Coll., on the residence of foreign nationals in the Czech Republic, in the wording of later regulations. Prague: Ministry of the Interior of the Czech Republic; 1999. (In Czech.)

26. Act No. 48/1997 Coll., on public health insurance and on revisions of some relevant acts. Prague: Ministry of the Interior of the Czech Republic; 1997. (In Czech.)

27. General Health Insurance Company of the Czech Republic. Annual report of the General Health Insurance Company of the Czech Republic 2007 [Internet]. Prague: B.I.G.; 2008 [cited 2010 Oct 10]. Available from: http:// www.vzp.cz/uploads/document/1293734219-vyrocni_zprava_2007.pdf. (In Czech.)
28. Hnilicová H, Dobiášová K. State of art report Czech Republic MIGHEALTHNET in the CR [Internet]. Prague: Charles University, First Faculty of Medicine - Institute of Public Health and Medical Law [cited 2010 Nov 10]. Available from http://mighealth. net/cz/images/d/dc/Zpr\%C3\%A1va_o_stavu_zdrav\%C3\%AD_ migrant $\%$ C $5 \%$ AF_v_\%C4\%8CR_na_we-b.pdf. (In Czech.)

29. Institute of Health Information and Statistics of the Czech Republic. Comparison of selected health indicators in EU and CR. Prague: Institute of Health Information and Statistics of the Czech Republic; 2004.

Received December 3, 2010 Accepted in revised form May 25, 2011 